\title{
Factors Influencing Inter-Pregnancy Interval among Antenatal Attendee in a Tertiary Hospital in Abakaliki, South-East, Nigeria
}

\author{
Chidebe Christian Anikwe ${ }^{1 *}$, Benjamin Samuel Umezuluike1, Brown Nnamdi Ejikeme1, \\ Okechukwu Emmanuel Ndukwe1, Bartholomew Chukwunonye Okorochukwu2, \\ Nworah Josaiah Obiechina ${ }^{3}$, Cyril Chijioke Ikeoha', Ogah Emeka Onwe ${ }^{4}$ \\ ${ }^{1}$ Department of Obstetrics and Gynaecology, Federal Teaching Hospital, Abakaliki, Nigeria \\ ${ }^{2}$ Department of Obstetrics and Gynaecology, Federal Medical Centre, Owerri, Nigeria \\ ${ }^{3}$ Department of Obstetrics and Gynaecology, Nnamdi Azikiwe University Teaching Hospital, Awka, Nigeria \\ ${ }^{4}$ Department of Paediatrics, Federal Teaching Hospital, Abakaliki, Nigeria \\ Email: ^drchideanikwechristian@gmail.com,drbenumez@gmail.com, henrybee2001@yahoo.com,ndukwe.emmanuel@yahoo.com, \\ barthychuks@gmail.com,nworahobiechina@yahoo.com, ikeohacyril@gmail.com, dronweogah@yahoo.com
}

How to cite this paper: Anikwe, C.C. Umezuluike, B.S., Ejikeme, B.N., Ndukwe, O.E., Okorochukwu, B.C., Obiechina, N.J., Ikeoha, C.C. and Onwe, O.E. (2018) Factors Influencing Inter-Pregnancy Interval among Antenatal Attendee in a Tertiary Hospital in Abakaliki, South-East, Nigeria. Open Journal of Obstetrics and Gynecology, 8, 1364-1375.

https://doi.org/10.4236/ojog.2018.813138

Received: October 7, 2018

Accepted: November 9, 2018

Published: November 12, 2018

Copyright $\odot 2018$ by authors and Scientific Research Publishing Inc. This work is licensed under the Creative Commons Attribution International License (CC BY 4.0).

http://creativecommons.org/licenses/by/4.0/

(c) (i) Open Access

\begin{abstract}
Background: World over, there has being an improvement in birth spacing resulting in a reduction in the perinatal and maternal morbidity and mortality rates. Objective: To appraise the factors influencing inter-pregnancy interval (IPI) among pregnant women receiving antenatal care at Federal Teaching Hospital Abakaliki. Methods: A descriptive cross-sectional study was done among antenatal attendee, with at least one previous delivery, in Federal Teaching Hospital, Abakaliki over a six month period using a structured questionnaire. Data obtained was analysed using IBM SPSS Statistics version 20. Results: The mean age of the respondents was 28.6 (95\% CI 28.1 $29.1)$ years. The majority $(231,70 \%)$ were multiparous. Most respondent $(162,49.1 \%)$ had their last delivery $6-12$ months prior to conception. The significant determinants of IPI include: maternal age, marital status, place of residence, social class, baby's sex, family income, use of contraceptive, parity and outcome of her last confinement. Contraceptive knowledge is high (300, $90.9 \%$ ); more than $50 \%$ had the desire to use some form of contraceptive but majority $(132,40 \%)$ said they will never use contraceptive after delivery. Conclusions: Majority of the women had an IPI of $6-12$ months. The major determinant of this includes having a live birth in last delivery, parity, marital status, and place of residence. The attitude to contraception is poor; effort needs to be directed into identifying the immediate and remote causes of this as this will help in proper education and counselling needed to increase contraceptive uptake.
\end{abstract}




\section{Keywords}

Abakaliki, Contraceptive Usage, Inter-Pregnancy Intervals

\section{Introduction}

Fertility is one of the important principal components of population dynamics that determine the size and structure of the population of a given country [1]. Given that fertility rates are high in sub-Saharan African countries, it is critically important to understand the determinants of child-spacing to inform population reduction policies [2]. The Nigerian national total fertility rate is 5.5 births per woman [3] and these high fertility levels are of major concern to planners and policy makers in most countries in the developing world [4]. The population of Nigeria represents $2.35 \%$ of the world's total population with a population growth rate of $2.8 \%$ [3]. It becomes necessary to elucidate the determinants of child spacing in our various homes in order to assist policy makers to avoid a population explosion.

Globally, maternal mortality has witnessed a significant reduction in the last 20 years and this has partly been due to the increased contraceptive use with consequent reduction in unintended pregnancies [5]. Birth spacing, therefore, is one of the strategies through which good maternal and child health can be achieved; thus the introduction of various intervening programmes such as family planning and safe motherhood programmes to enhance longer spacing of births for maternal and child health [6]. Birth spacing interval has been a subject of interest to health researchers because of its important bearing on maternal and child health and survival [7].

Birth spacing/interval is the time between successive live births [1] [8] [9]. Optimal spacing between pregnancies has greater health advantages for both mother and child, which can give opportunity for the mother to recover from pregnancy, labour and lactation [1]. Timing of births may be inversely related to completed or cumulative fertility [8]: the longer the interval, the lower the fertility levels [4]. Short birth interval is associated with diverse complications that are detrimental to the health of both succeeding child and to the mother [9] [10]. Prolonged birth spacing, on the other hand, has been shown to put women at risk of pregnancy and labour complications [7]. It therefore becomes pertinent to find the determinants of birth spacing. At least 24 months have been recommended as the minimum interval before attempting the next pregnancy after a live birth resulting in a minimum birth interval of 33 months while a minimum of 6 months have been recommended after a miscarriage or induced abortion [10] [11]. The biological and behavioral mechanism by which shorter intervals affect infant and maternal morbidity and mortality are maternal depletion, premature delivery, milk diminution, and sibling rivalry [7].

Worldwide, women differ widely in their birth spacing practices. A variety of 
factors influences women's birth spacing practices, such as sex of child, birth order, mother's age at birth, mother's education, occupation, urban/rural residence, type of provider of prenatal care and index of household wealth. These factors and more such as modern contraceptive use and state of her previous child influence birth spacing practices in most parts of the world including Nigeria [1] [2] [4] [5] [8] [9] [10] [11]. This study aims to assess the factors influencing child spacing among women receiving antenatal care in a tertiary hospital in Abakaliki, South-East, Nigeria.

\section{Materials and Methods}

\subsection{Study Area}

The study was carried out at Federal Teaching Hospital Abakaliki, Ebonyi State between March and July 2016. It is the only tertiary health institution in the state receiving referral from private, primary and secondary health facilities in the state and neighboring state. It has 11 clinical departments of which Obstetrics and Gynaecology is one of them. The Obstetrics and Gynaecology department is managed by 27 consultants and 90 residents' doctors with the help of trained nurses. It has 10 units and runs antenatal and booking clinic daily during the working days. It has an average of 203.5 deliveries per month. It has an operation room staffed $24 / 7$ by nurses and obstetricians capable of performing caesarean sections and also a good blood banking services. The department has a well woman clinic and family planning unit that offers among others cervical screening and contraceptive advice and counselling to clients.

Ebonyi state is one of the states in South-East Nigeria with a total population of more than 1.7 million according to 2006 Nigeria national census. It shares boundary with the following states in Nigeria which are: Enugu, Cross-River, Abia and Benue. The main occupation of the people is farming. Ethical approval for the study was obtained from the Research and Ethics committee of the hospital.

\subsection{Study Design}

This was a cross-sectional analytical study.

\section{Study Population/Sample Size}

The study population was women who consented to participate in the study. They were women who are accessed to be booked at the facility. Women who are booked refer to women who have attended at least three visits in the hospital, have done their baseline booking investigations and have been reviewed by a doctor. Those who refused to consent or those who are sick are excluded. Following the general antenatal health education/talk by the nurses, the general antenatal attendees are informed on the study and their consent sort. The sample size for the study was 348 after addition of $10 \%$ attrition rate; it was increased to 350. It was estimated using the formula for cross-sectional study at estimated population of $29 \%$ [3], acceptable error of $5 \%$ at confidence level of $95 \%$. Antenat- 
al clinic attendance register served as the sampling frame. Those who met the inclusion criteria were selected using systematic sampling method. Since an average of 100 women came for ANC each day, the sampling interval of four (4) was calculated from the total sample size of 348 . The $n t h, n+k$ th, $n+2 k t h, n+3 k$ th, $\mathrm{n}+4 \mathrm{kth}$ etc. study population was selected. They were recruited between March and July 2016. They were interviewed using a semi-structured questionnaire adapted. Consenting women who are literate would be asked to fill the questionnaire while those who are not literate was interviewed alone in one of the office dedicated for the study by trained research assistance. The questionnaire was filled based on their response. Some of the information obtained included the socio-demographic characteristics of the study population: age, marital status, occupation, level of education, religion, spouse education, occupation etc.; parity, number of living children, booking status in her last pregnancy, number of visits, place of booking/delivery and outcome of pregnancy was also obtained. The social class of the study population was determined based on the social class classification of Olusanya et al. [12]. The educational level of the women and the occupation of the husband were used in the classification. The social class of the study participants that were not married was based on that of their parent. They were graded into social class 1 to 5 . Social class 1 and 2 represent upper social class; social class 3 represents middle class while social class 4 and 5 represent lower social class. Inter-pregnancy interval was defined as the duration of time from the delivery of last child to the last menstrual period of an on-going pregnancy. Permission to carry out this research was sought and obtained from the Research and Ethical Committee of the Federal Teaching Hospital Abakaliki.

\subsection{Data Analysis}

The data obtained was analyzed using IBM SPSS Statistics version 20 (IBM Corp., Armonk, NY, USA). For easy analysis, the data obtained were re-categorized thus; age < 30 years, $\geq 30$ years; social class: upper social class (social class 1, 2 and 3), lower social class (social class 4 and 5); Inter pregnancy interval $\leq 1$ year, $>1$ year; parity $<4, \geq 4$; no of children $<4, \geq 4$ and outcome of last pregnancy alive and not alive. The results were presented in frequency tables, chi square and odd ratio. Level of significance is at $\mathrm{P}<0.05$.

\section{Results}

The mean age of the respondent was 28.6 years (95\% CI $28.1-29.1$ ). Majority $(244,72.8 \%)$ of the respondent were within the age bracket of 25 - 34 years. More than half of the women had tertiary education as their highest level of education attained. Civil service job constitute the commonest type of occupation (138, $42 \%)$. Family income was "not enough" in about one quarter of the women (Table 1).

From Table 2, majority (231,70\%) of the respondents were multiparous. More than $90 \%$ of the study population was delivered of a live neonate in their 
Table 1. Socio-demographic characteristics.

\begin{tabular}{|c|c|c|}
\hline Variables & Frequency (n) & Percentage (\%) \\
\hline \multicolumn{3}{|l|}{ Age (years) } \\
\hline $15-19$ & 12 & 3.6 \\
\hline $20-24$ & 48 & 14.5 \\
\hline $25-29$ & 126 & 38.2 \\
\hline $30-34$ & 114 & 34.6 \\
\hline $35-39$ & 27 & 8.2 \\
\hline $40-44$ & 3 & 0.9 \\
\hline \multicolumn{3}{|l|}{ Marital status } \\
\hline Married & 327 & 99.1 \\
\hline Single & 3 & 0.9 \\
\hline \multicolumn{3}{|l|}{ Residence } \\
\hline Urban & 258 & 78.2 \\
\hline Rural & 72 & 21.8 \\
\hline \multicolumn{3}{|l|}{ Ethnicity } \\
\hline Igbo & 309 & 93.6 \\
\hline Hausa & 9 & 2.7 \\
\hline Yoruba & 12 & 3.6 \\
\hline \multicolumn{3}{|l|}{ Religion } \\
\hline Christian & 321 & 97.3 \\
\hline Muslim & 9 & 2.7 \\
\hline \multicolumn{3}{|l|}{ Occupation } \\
\hline Farming & 24 & 7.3 \\
\hline Trading & 105 & 31.8 \\
\hline Civil servant & 138 & 41.8 \\
\hline House wife & 57 & 17.3 \\
\hline Student & 6 & 1.8 \\
\hline \multicolumn{3}{|l|}{ Education } \\
\hline Primary & 57 & 17.3 \\
\hline Secondary & 87 & 26.4 \\
\hline Tertiary & 186 & 56.4 \\
\hline \multicolumn{3}{|l|}{ Social class } \\
\hline Upper class & 195 & 55.7 \\
\hline Lower class & 155 & 44.3 \\
\hline \multicolumn{3}{|l|}{ Family income } \\
\hline Enough & 135 & 40.9 \\
\hline Enough and save & 120 & 38.4 \\
\hline Not enough & 75 & 22.7 \\
\hline
\end{tabular}

Table 2. Obstetric performance of the study population.

\begin{tabular}{ccc}
\hline Obstetric characteristic & Frequency $(\mathrm{n})$ & Percentage $(\%)$ \\
\hline Parity & & \\
1 & 99 & 30.0 \\
$2-4$ & 177 & 53.6 \\
$>4$ & 54 & 16.4 \\
\hline
\end{tabular}




\section{Continued}

\begin{tabular}{|c|c|c|}
\hline Live & 306 & 92.7 \\
\hline Stillbirth & 12 & 3.6 \\
\hline Abortion & 12 & 3.6 \\
\hline \multicolumn{3}{|l|}{ Sex of last baby } \\
\hline Male & 162 & 49.1 \\
\hline Female & 168 & 50.9 \\
\hline \multicolumn{3}{|l|}{ № of living children } \\
\hline 1 & 105 & 31.8 \\
\hline $2-4$ & 162 & 49.1 \\
\hline$>4$ & 63 & 19.1 \\
\hline \multicolumn{3}{|c|}{ History of child death } \\
\hline Yes & 45 & 13.6 \\
\hline No & 285 & 86.4 \\
\hline \multicolumn{3}{|c|}{ History of abnormal child } \\
\hline Yes & 9 & 2.7 \\
\hline No & 321 & 97.3 \\
\hline \multicolumn{3}{|l|}{ Breastfeeding } \\
\hline$<6$ months & 57 & 17.3 \\
\hline $6-12$ months & 189 & 57.3 \\
\hline$>12$ months & 66 & 20.0 \\
\hline No breastfeeding & 18 & 5.5 \\
\hline \multicolumn{3}{|c|}{ Inter-pregnancy interval } \\
\hline$<6$ months & 9 & 2.7 \\
\hline $6-12$ months & 162 & 49.1 \\
\hline $13-24$ months & 126 & 38.2 \\
\hline$>24$ months & 33 & 10.0 \\
\hline
\end{tabular}

last confinement; the stillbirth rate was 36.4 per 1000 deliveries. About $50 \%$ of the women under study conceived between $6-12$ months after their last delivery. Eighteen (5.5\%) mothers did not breast feed their because of being screened positive to HIV. Women that had spontaneous vaginal delivery had shorter interval (6 - 12 months) compared to women that had Caesarean section or instrumental vaginal delivery.

Majority $(300,90.9 \%)$ of the respondent are aware of different forms of contraceptive methods while 195 (59\%) expressed a desire to use contraception after delivery. Among respondents that are willing to use, majority $(81,24.6 \%)$ will like to use it immediately after delivery. However, $132(40 \%)$ of the respondents opted never to use any form of contraceptives (Table 3 ).

Table 4 shows the determinants of inter pregnancy interval. The outcome of last pregnancy, parity, marital status and place of residence are strong determinant of pregnancy interval greater than one (1) year. Women with a live baby, four or more delivery, residing in rural setting and been married are associated with less than $50 \%$ odd of delaying pregnancy for more than one year. Cohort of women on contraceptive have $82 \%$ less odd of delaying pregnancy for more than one (1) year with true effect lying between $99.8 \%$ - 99.9\%. Study population with 
Table 3. Contraceptive awareness and desire for use.

\begin{tabular}{ccc}
\hline Variables & Frequency $(\mathrm{n})$ & Percentage $(\%)$ \\
\hline Awareness & 300 & \\
Yes & 30 & 90.9 \\
No & & 9.1 \\
Desire for use & 195 & \\
Yes & 135 & 59.1 \\
No & & 40.9 \\
& & \\
How soon to use after delivery & 81 & 24.6 \\
Immediately & 69 & 20.9 \\
$6-12$ months & 33 & 10.0 \\
$13-24$ months & 15 & 4.5 \\
$>24$ months & 132 & 40.0 \\
Never & &
\end{tabular}

Table 4. Cross-tabulation of various characteristics of respondents with inter-pregnancy interval.

\begin{tabular}{|c|c|c|c|}
\hline \multirow{2}{*}{ Variables } & \multicolumn{2}{|c|}{ Inter pregnancy interval } & \multirow{2}{*}{ OR 95\% CI; $\mathrm{X}^{2} \mathrm{P}$ value } \\
\hline & $\leq 1$ year & $>1$ year & \\
\hline \multicolumn{4}{|l|}{ Age (years) } \\
\hline$<30$ & 171 & 15 & \multirow{2}{*}{$0.08 ; 0.05-0.13^{\dagger}$} \\
\hline$\geq 30$ & 0 & 144 & \\
\hline \multicolumn{4}{|l|}{ Marital status } \\
\hline Married & 171 & 156 & \multirow{2}{*}{$0.47 ; 0.42-0.53^{\dagger}$} \\
\hline Single & 0 & 3 & \\
\hline \multicolumn{4}{|l|}{ Residence } \\
\hline Urban & 171 & 87 & \multirow{2}{*}{$0.34 ; 0.28-0.40^{\dagger}$} \\
\hline Rural & 0 & 72 & \\
\hline \multicolumn{4}{|l|}{ Social class } \\
\hline Upper & 171 & 24 & \multirow{2}{*}{$0.12 ; 0.08-0.18^{\dagger}$} \\
\hline Lower & 0 & 135 & \\
\hline \multicolumn{4}{|l|}{ Educational status } \\
\hline Sec. \& below & 105 & 0 & \multirow{2}{*}{$3.41 ; 2.78-4.18$} \\
\hline Tertiary & 66 & 159 & \\
\hline \multicolumn{4}{|l|}{ Family income $e^{*}$} \\
\hline Enough & 135 & 0 & \multirow{3}{*}{$\begin{array}{c}X^{2}(2)=229.01 \\
P=0.001^{\star}\end{array}$} \\
\hline Enough and save & 36 & 84 & \\
\hline Not enough & 0 & 75 & \\
\hline \multicolumn{4}{|l|}{ Contraceptive use } \\
\hline Yes & 171 & 24 & \multirow[t]{2}{*}{$0.12 ; 0.08-0.18^{\dagger}$} \\
\hline No & 0 & 135 & \\
\hline \multicolumn{4}{|l|}{ Parity } \\
\hline$<4$ & 171 & 18 & \multirow{2}{*}{$0.40 ; 0.35-0.48^{\dagger}$} \\
\hline$\geq 4$ & 0 & 141 & \\
\hline
\end{tabular}




\section{Continued}

Number of living children

$<4$

$\geq 4$

Outcome of last pregnancy

Alive

Not alive

Sex

Female

Male

171

0

9

162
159

0

135

24

159

0

${ }^{*}$ chi square, ${ }^{\dagger}$ statistically significant.

highest of secondary school and below are 3.4\% more likely than cohort with tertiary education to conceive a year or less after delivery although not significant. There is an association between the sex of neonate in last delivery with IPI $\left(\mathrm{X}^{2}(1)=295.8, \mathrm{P}=0.001\right)$

\section{Discussion}

Birth spacing has become a major health promotion program strategy for mothers in recent years especially in the developing countries. Optimal inter-pregnancy interval brings about an improvement in maternal and perinatal outcome following delivery [13]. This study has demonstrated that there is a relationship between inter-pregnancy interval and some socio-demographic and obstetrics characteristics of the study population. The mean age of the women in our study was 28.6 years; most of the women had tertiary education and belonged to upper social class. The observed mean age of women in our study agrees with a similar work in Ogbomoso by Owonikoko et al. [5]. Majority of women in their study had secondary education and belonged to lower social class which is at variance with our study population. This difference was also observed in the report of Begna et al. in Ethiopia [1] where more than $70 \%$ of women studied had no formal education belonging to low social class. The mean age, 28.6 years $(95 \% \mathrm{CI}$ 28.1 - 29.1), observed in our study is in tandem with the finding of 2013 Nigerian National Demographic and Health Survey [3] as age range with highest fertility rate in Nigeria.

The birth weight of newborns serves as one of the major determinants for physical and mental growth in infants [14]. It is a reflection of the intrauterine growth of the fetus which is affected by the maternal well-being before embarking on pregnancy. Zhang et al. [14] in their analysis of the relationship between inter pregnancy interval and neonatal weight reported that short IPI of less than one year had negative effects at the 5th and 10th quantiles of the birth weight distribution unlike when the IPI is longer although this benefit is loss with much longer IPI. This might be attributed to depletion of maternal nutritional store that can occur with frequent and close pregnancies [15] and subsequent adverse 
neonatal outcome [16]. Majority of women in our study had IPI of 6 - 12 months which might be associated with negative effect on the mother and her new born. This is below the Nigerian national figure [3] and WHO recommendation of a minimum of 2 years of IPI [14]. This short IPI seen in our study might be attributed to inadequate use of effective method of contraception which can be inferred from our respondents. Even though majority are educated with good awareness of method of contraception; majority are not willing to use it. This finding corroborates earlier findings in Nigeria [3]. The fact that more than ninety percent of our respondent are in a stable relationship and have enough income might influence this short IPI seen in our study. Our findings however differs from the work of Owonikoko et al. in Ogbomoso where majority of the women they studied had an inter-pregnancy interval of $>24$ months [5]. The differences in study area and study population are possible explanation of these findings as majority of respondent in Owonikoko et al. [5] defers pregnancy because of academic pursuit.

Maternal age, marital status, place of residence, social class, baby's sex, family income, use of contraceptive, parity and outcome of her last confinement are the factors that significantly influence the IPI in our study. With the exemption of family income and number of living children other factors are associated with varying odds of having an IPI that is greater than one year. Having a live birth, four or more children, being single and residing in rural area are associated with higher significance of IPI that is greater than one year which is made evident by their odds and confidence interval. The findings from our study corroborate earlier reports [1] [5] [17]. It is apparent from our study that the use of contraceptives does not contribute to higher percentage of women having an IPI of more than one year. For those that are using any form of contraception the odds is less than one. The possible reason that might explain this finding possibly lies in the nature of contraceptive used and how consistent these women are with the one they are using. The use of modern method of contraceptive is low in the study area [3] as majority prefers natural family planning method that has a low Pearl index with the attendant unplanned pregnancy. As might be expected the cohort of women in our study that has the highest level of education of secondary school and below have increased odds of IPI that is less than one year. Lack of use of effective modern method of contraceptive is a plausible reason. About $30 \%$ of the women would like to use an effective contraceptive method between 6 and 24 months after delivery. However, about 40\% of the respondents do not desire to use contraceptives. This result is higher than $18.1 \%$ reported by Dim et al. in their study in Enugu [18]. This difference could be attributed to the higher mean age of the respondents of about 31 years in the study in Enugu [18] as these women may not want to delay pregnancy because of decrease in fertility that occurs with increasing age.

The obstetric performances of the respondents were found to influence their inter-pregnancy intervals. It was found that women who had stillbirth or whose 
pregnancies were aborted had shorter interval compared with women that had live babies. This is similar to the finding by Owonikoko et al. [5] that showed short inter-pregnancy interval in women that lost their last pregnancy [5]. This may be due to a compelling need to replace the lost pregnancy as well as early return of fertility in such category of women due to loss of the contraceptive effects of breastfeeding especially exclusive breastfeeding. Mode of delivery in the last pregnancy was also found to play a significant role in determining the inter-pregnancy interval as women that had spontaneous vaginal delivery had shorter interval (6 - 12 months) compared to women that had Caesarean section or instrumental vaginal delivery. This may be due to the longer period required for recovery and consequent late resumption of coitus after Caesarean section. Following Caesarean section, women are advised to delay pregnancy for about 12 - 18 months [19], to minimize the risk of uterine rupture and other attendant morbidities and possible mortalities. It was observed from this study, that about $57 \%$ of women breastfed their babies for a duration of $6-12$ months which is shorter than the period of about 18 months reported in the NDHS 2008 [20] while $78 \%$ of the respondents practiced exclusive breastfeeding for at least first 6 months. This figure is much higher than 17\% reported by the NDHS 2013 for exclusive breastfeeding [3] and 13\% reported in the 2008 survey [20]. This variation may be due to higher sample size, predominance of educated couples in this study and increased awareness of contraceptive and economic importance of breastfeeding and especially exclusive breastfeeding.

\section{Conclusion}

In conclusion, the study demonstrated that strong statistical significance exists between marital status, place of residence, family income, parity and outcome of her last confinement and inter-pregnancy interval among pregnant women in the study area. The apparent less contribution of contraception to IPI is worrisome and effort should be made by government and Non-Governmental Agencies (NGO) to improve utilization of modern method of contraception. It is important that obstetric population in the study area and Nigeria in general should be educated of the importance of adequate IPI in improving maternal and child health indices. Antenatal classes in an important arena to embark on this and should be properly utilized.

\section{Limitation(s) of the Study}

The findings from this study cannot be generalized in the study area as only a cohort of women that came for ante natal care in the hospital where studied. Also the re-classification of data for easy analysis in the index study is not based on a previous study which might make comparison with other studies difficult. Some of the groups in our study have zero representation based on our re-classification which made it impossible for calculation of odd ratio in some arms and thus inferences on them cannot be made. 


\section{Acknowledgements}

We want to appreciate the women who participated in the study with whom the study will not have been possible. We want to express our gratitude also to the Registrars that assisted us in administration of the questionnaire.

\section{Declarations}

Ethics approval and consent to participate: Ethical approval for the study was obtained from the Research and Ethics committee of the hospital.

\section{Availability of Data and Material}

All data generated or analysed during this study are included in this published article.

\section{Funding}

Funding is borne by the authors.

\section{Authors' Contributions}

CCA \& BSU: participated in the study design, data collection/analysis and interpretation of finding and drafting of manuscript. BNE \& BCO: participated in the interpretation of findings and data analysis. JAO: participated in study design, interpretation of findings and drafting of manuscript. CCI: conceptualized the study and participated in the interpretation of finding, NJO \& OEO: participated in the interpretation of findings and writing of manuscript. All participated in the review of final manuscript. All the authors approved the manuscript.

\section{Conflicts of Interest}

The authors declare that they have no competing interests.

\section{References}

[1] Began, Z., Assegid, S., Kassahun, W. and Gerbaba, M. (2013) Determinants of Inter-Birth Interval among Married Women Living in Rural Pastoral Communities of Southern Ethiopia: A Case Control Study. BMC Pregnancy Childbirth, 13, 116. https://doi.org/10.1186/1471-2393-13-116

[2] Kodzi, I.A., Johnson, D.R. and Casterline, J.B. (2012) To Have or Not To Have Another Child: Life Cycle, Health and Considerations of Ghanaian Women. Social Science \& Medicine, 74, 966-972. https://doi.org/10.1016/j.socscimed.2011.12.035

[3] National Population Commission [Nigeria] and ICF International (2014) 2013 Nigeria Demographic and Health Survey. NPC and ICF International, Abuja and Rockville.

[4] Moataz, A.F., Tamer, H., Tarek, I.E., Maha, M.M. and Mahmoud, A.M. (2007) Determinants of Birth Spacing among Saudi Women. Journal of Family and Community Medicine, 14, 103-111.

[5] Owonikoko, K.M., Adeniji, O., Oke, O.F., Fawole, A.A. and Adeniji, A.O. (2015) Determinants of Inter-Pregnancy Interval in Ogbomoso: An Unmet Need for Con- 
traceptive Usage. International Journal of Reproduction, Contraception, Obstetrics and Gynecology, 4, 316-321. https://doi.org/10.5455/2320-1770.ijrcog20150406

[6] Osakue, S.O. (2010) Broadcast Media in Family Planning Matters in Rural Nigeria: The Ebelle Scenario. Journal of Communication, 1, 77-85. https://doi.org/10.1080/0976691X.2010.11884773

[7] Orji, E.O., Shittu, A.S., Makinde, O.N. and Sule, S.S. (2004) Effects of Prolonged Birth Spacing on Maternal and Perinatal Outcome. East African Medical Journal, 81, 388-391. https://doi.org/10.4314/eamj.v81i8.9198

[8] Gyimah, S.O. (2005) The Dynamics of Timing and Spacing of Births in Ghana. Journal of Comparative Family Studies, 36, 41-60.

[9] Tessema, G.A., Zeleke, B.M. and Ayele, T.A. (2013) Birth Intervals and Its Predictors among Married Women in Dabat District, Northwest Ethiopia: A Retrospective Follow-Up Study. African Journal of Reproductive Health, 17, 39-45.

[10] Rutstein, S.O. (2011) Trends in Birth Spacing. DHS Comparative Reports No.28. ICF Macro, Calverton, Maryland, USA.

[11] CCP and WHO (2007) Family Planning: A Global Handbook for Providers.

[12] Olusanya, O., Okpere, E.E. and Ezimokhai, M. (1985) The Importance of Social Class in Voluntary Fertility Control in a Developing Country. West African Journal of Medicine, 4, 205-207.

[13] Wendta, A., Gibbsb, C.M., Petersb, S. and Hogue, C.J. (2012) Impact of Increasing Inter-Pregnancy Interval on Maternal and Infant Health. Paediatric and Perinatal Epidemiology, 26, 239-258. https://doi.org/10.1111/j.1365-3016.2012.01285.x

[14] Zhang, Q., Dang, S., Bai, R., Mi, B., Wang, L. and Yan, H. (2018) Association between Maternal Interpregnancy Interval after Live Birth or Pregnancy Termination and Birth Weight: A Quantile Regression Analysis. Scientific Reports, 8, 4130. https://doi.org/10.1038/s41598-018-22498-0

[15] Merklinger-Gruchala, A., Jasienska, G. and Kapiszewska, M. (2015) Short Interpregnancy Interval and Low Birth Weight: A Role of Parity. American Journal of Human Biology: The Official Journal of the Human Biology Council, 27, 660-666. https://doi.org/10.1002/ajhb.22708

[16] Hanley, G.E., Hutcheon, J.A., Kinniburgh, B.A. and Lee, L. (2017) Interpregnancy Interval and Adverse Pregnancy Outcomes an Analysis of Successive Pregnancies. Obstetrics \& Gynecology, 129, 408-415.

[17] Hailu, D. and Gulte, T. (2016) Determinants of Short Interbirth Interval among Reproductive Age Mothers in Arba Minch District Ethiopia. International Journal of Reproductive Medicine, 2016, Article ID: 6072437.

[18] Dim, C.C., Ugwu, E.O. and Iloghalu, E.I. (2013) Duration and Determinants of Interbirth Interval among Women in Enugu, South-Eastern Nigeria. Journal of $\mathrm{Ob}$ stetrics and Gynaecology, 33, 175-179. https://doi.org/10.3109/01443615.2012.747494

[19] Idrisa, A. (2005) Infertility. In: Kwawukume, E.Y. and Emuveyan, E.E., Eds., Comprehensive Gynaecology in the Tropics, Graphics Packaging, Accra, 333-345.

[20] National Population Commission (NPC) (2009) [NIGERIA] and ICF Macro. 2009. Nigeria Demographic and Health Survey 2008, Abuja. 